\title{
Genetic footprints of medieval nomads on the crossroads of civilizations in Southern Russian
}

\author{
A. Mikheyev, E. Batyeva, V. Klyuchniov, Yu. Orlov, N. Moshkov, I. Dmitrievsky, \\ T. Lorentz, T. Tatarinova* \\ University of La Verne, CA, USA \\ *e-mail: tatiana.tatarinova@gmail.com
}

Key words: human genetics, population genetics, genome, paleogenetics, evolution

Investigations of human origin sparkles numerous debates. Emergence of consumer genetics and genotyping of thousands of individuals around the globe did nothing to calm these debates - just the opposite. A person (or a group of people) who have nothing in common genetically with the ethnic group with which they identify culturally, will naturally, contest and oppose the findings. It is human to be nervous about our genomes. We do not see it, but we have a copy of this genome in every cell of our body. And this invisible but powerful thing makes us who we are, determines kinship, sets limitations and pre-determines illnesses. It is very human to fear such ghostly unharnessed power. The potential to control human genome is even scarier to many people. Genetics has the power to rewrite family and country histories, uncover infidelities, and challenge ownership.

We have conducted anthropological and genetic analysis of three skeletons from the burial sites in Southern Russia, dated early-middle $9^{\text {th }}$ century AD. In this talk, we will present our analysis pipeline, talk about the hurdles and lessons we learned from overcoming them, and formulate a hypothesis about the trace of early medieval nomads in genomes of contemporary eastern Europeans. 